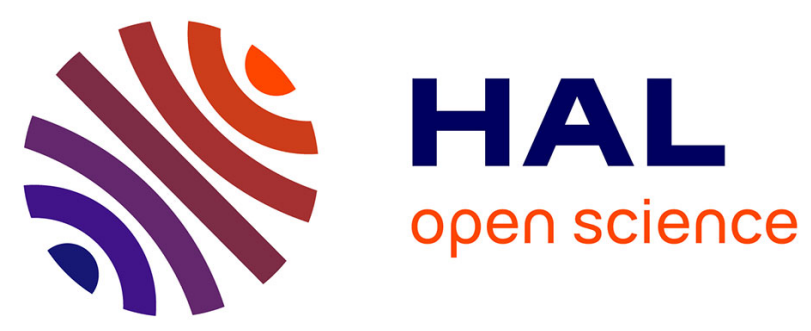

\title{
Experimental investigation of the tribological behavior and wear mechanisms of tool steel grades in hot stamping of a high-strength boron steel
}

\author{
Christine Boher, Sabine Le Roux, Luc Penazzi, C. Dessain
}

\section{To cite this version:}

Christine Boher, Sabine Le Roux, Luc Penazzi, C. Dessain. Experimental investigation of the tribological behavior and wear mechanisms of tool steel grades in hot stamping of a high-strength boron steel. Wear, 2012, 294, pp.286-295. 10.1016/j.wear.2012.07.001 . hal-01687327

\section{HAL Id: hal-01687327 https://hal.science/hal-01687327}

Submitted on 25 Sep 2018

HAL is a multi-disciplinary open access archive for the deposit and dissemination of scientific research documents, whether they are published or not. The documents may come from teaching and research institutions in France or abroad, or from public or private research centers.
L'archive ouverte pluridisciplinaire HAL, est destinée au dépôt et à la diffusion de documents scientifiques de niveau recherche, publiés ou non, émanant des établissements d'enseignement et de recherche français ou étrangers, des laboratoires publics ou privés. 


\title{
Experimental investigation of the tribological behavior and wear mechanisms of tool steel grades in hot stamping of a high-strength boron steel
}

\author{
C. Boher ${ }^{\mathrm{a}, *}$, S. Le Roux ${ }^{\mathrm{a}}$, L. Penazzi ${ }^{\mathrm{a}}$, C. Dessain ${ }^{\mathrm{b}}$ \\ a Université de Toulouse; Mines Albi, ICA (Institut Clément Ader), Campus Jarlard, F-81013 Albi cedex 09, France \\ ${ }^{\mathrm{b}}$ ArcelorMittal Global Research and Development Montataire, 1 route de Saint Leu, 60761 Montataire Cedex, France
}

\begin{abstract}
A B S T R A C T
In this study, the high temperature wear behavior of hot forming tool steel grades is investigated by successive sliding of a pre-alloyed Usibor $1500 \mathrm{P}^{\mathbb{R}}$ strip heated at high temperature. Experimental tests are performed at high temperature on an instrumented Deep-Drawing Process Simulator (DDPS). This laboratory pilot is employed to rank different steel grades used as tool materials in the hot-stamping process. The wear damage of the tool (die radius) is characterized by profilometry and SEM observations, and three quantitative criteria are determined from 2D profile measurements to assess adhesive and abrasive wear. Under examined conditions at high temperature, a predominant transfer mechanism is observed, while abrasive wear appears as minor damage. When the surface hardness of the tool material is not great enough, the sub-surface of the die radius can exhibit a plastic shear deformation of about $10 \mu \mathrm{m}$ in depth. This leads to emission of wear debris coming from the cumulated cyclic plastic deformation of the sub-surface. In contrast, for high surface hardness, the adhesive wear rapidly reaches an asymptotic state.
\end{abstract}

Keywords:

Wear mechanisms

Tool steel grades

Profilometry

Surface damage criteria

Hot sheet metal forming

\section{Introduction}

In recent years, the technology of hot-stamping of boron steel has experienced remarkable improvement for the design of new body-in-white structures, as material and process innovations seek to meet the major objectives of the automotive industry: improvement of the crashworthiness of cars, weight saving (with direct impact on the $\mathrm{CO}_{2}$ emissions), and cost-effective steel making for mass production [1]. This rapid growth has been significantly accelerated by the introduction to the market of a patented aluminum-silicon-coated $22 \mathrm{MnB} 5$ boron-manganese hot-rolled alloyed steel, specifically tailored for this application by ArcelorMittal and commercialized under the trade name of Usibor $1500 \mathrm{P}^{\circledR}$. This grade is designed to obtain required properties after austenitizing, transfer to the press, forming and quenching in the closed tools. During this direct hot-stamping process cycle, the initial ferritic-pearlitic microstructure of the steel at the delivery state is transformed into a martensitic microstructure. This transformation confers an ultimate strength to the steel of around $1500 \mathrm{MPa}$, with a yield strength of around $1100 \mathrm{MPa}$.

\footnotetext{
* Corresponding author. Tel.: +33 563493169; fax: +33 563493099

E-mail addresses: Christine.boher@enstimac.fr, Christine.boher@mines-albi.fr (C. Boher).
}

No springback or shape deviation is observed after removing the part from the tools. The Al-Si coating, deposited by hot dipping the coil in an A-Si bath, protects the steel from scaling and surface decarburization during the heat treatment. Some authors estimate that the Al-Si coating could contribute to the friction and die-wear reduction [2].

During hot stamping, working tools are subjected to severe conditions. The combination of temperature and friction can lead to short maintenance intervals and high tool-maintenance costs. The solicitations undergone by the tool are complex: its surface interaction with the metal strip results in adhesion, abrasive wear, thermal stresses and fatigue. Consequently, the wear resistance of the hot stamping tools needs to be optimized. Optimization will maintain the dimensional tolerances of the hot stamped parts, guarantee a very good contact between the die and the sheet (which is the condition to obtain an efficient heat transfer and a stable quality of the mechanical properties of the final parts), and, finally, increase the maintenance intervals and drastically reduce maintenance costs.

In the literature, several authors have studied wear behavior in a friction process using specific tribological tests, in order to characterize different tool steel grades, with and without coating, at elevated temperature. With a reciprocating friction and wear test machine, Hardell et al. [3-5] evaluated the specific wear rate and the friction coefficient of different tool steels with and 
without nitriding. They focused their study on the tool wear behavior, and showed that an increase in temperature induces a decrease in the friction coefficient, whereas the wear of the tool steel increases with temperature. The wear of the Al-Si coating is significantly lower at $800{ }^{\circ} \mathrm{C}$ than at $40{ }^{\circ} \mathrm{C}$ or $400{ }^{\circ} \mathrm{C}$. The main wear mechanism appears to be adhesive wear at all temperatures coupled with a contribution from the abrading action of oxidized wear debris at elevated temperatures [3]. In addition, they conclude that nitriding of the tool steel provides better protection against severe wear [3-4].

Electro-plated $\mathrm{Zn}$-Ni-coated sheets were studied by Kondratiuk et al. [6]. They showed that the formation of a $\mathrm{ZnO}$ oxide scale at high temperature significantly reduces the friction coefficient and adhesion at the tool surface, compared with an $\mathrm{Al}-\mathrm{Si}$ coated sheet. In that study, the sheet was heated at $880{ }^{\circ} \mathrm{C}$ or $920^{\circ} \mathrm{C}$ in a furnace before testing.

Even if adhesion is influenced by test temperatures, a previous study [7] has revealed that the friction coefficient between the strip and the die radius is at a maximum when the strip exit angle $(\alpha)$ ranges between $70^{\circ}$ and $80^{\circ}$. In this case, the main wear damage observed on the die radius surface is adhesion of particles emitted from the steel strip, whereas a $90^{\circ}$ angle leads to surface ploughing. Groche et al. [8] developed a common model for conventional aluminum deep-drawing processes, in order to evaluate the adhesive wear. The calculations illustrate that adhesive wear occurs as a result of local high-peak stresses, due to the bending and unbending of the strip when sliding on the die radius. These studies revealed that the mechanism of adhesive wear depends on the temperature and the mechanical behavior of the strip [7-8].

In general, tribological macroscopic data (like friction coefficient evolution, gravimetric wear mass loss, and wear rate) are reported in the literature. Only a few studies deal with the quantification of microscopic local wear damage, such as adhesion and abrasion. At laboratory scale, this damage can be analyzed or estimated from profilometric or topographic measurements. However, because of the complex geometry of the die radii, only the most common roughness parameters are usually examined, especially for the strip, and rarely for the die [9-10].

As mentioned above, the lifetime of tools in hot stamping is an important element in the cost and quality of automobile parts. In this paper, the wear damage of different tool steel grades is investigated in the hot sheet-metal-forming process. Profilometric measurements and SEM cross-sectional observations are undertaken to study the wear mechanisms during the friction between the steel sheet and the die radius at high temperature. Wear criteria, determined from 2D profiles, are used to quantify the adhesive and abrasive wear magnitude of the die-radii. The results are focused only on die-radius degradation, with the wear of the strip not being considered. A precise description of the measurement procedure and definition of the wear damage criteria is reported in [11].

\section{Test materials}

\subsection{Die materials}

Three different grades of steel, developed by ArcelorMittal and its industrial partners, were studied:

Steel grade 1 (SG1)

The first tool steel grade is a X50CrMoV5 alloyed steel. The chemical composition is given in Table 1. Microstructural observations of the material reveal a fine and homogeneous martensitic structure in depth, with some iron and vanadium carbides of a few hundreds of nanometers. To improve its wear resistance, the
Table 1

Chemical composition (in wt.\%) of the investigated tool steels.

\begin{tabular}{llllll}
\hline Steel & $\mathrm{C}$ & $\mathrm{Cr}+\mathrm{Mo}$ & $\mathrm{Mn}+\mathrm{V}$ & Si and others & Fe \\
\hline Grade 1 (SG1) & 0.45 & $7-8$ & $1-2$ & 0.20 & $\mathrm{bal}$ \\
Grade 2 (SG2) & 0.54 & $5-6$ & $1-2$ & $1-2$ & $\mathrm{bal}$ \\
Grade 3 (SG3) & 0.32 & $4-5$ & $0.1-0.3$ & $3-4$ & $\mathrm{bal}$ \\
\hline
\end{tabular}

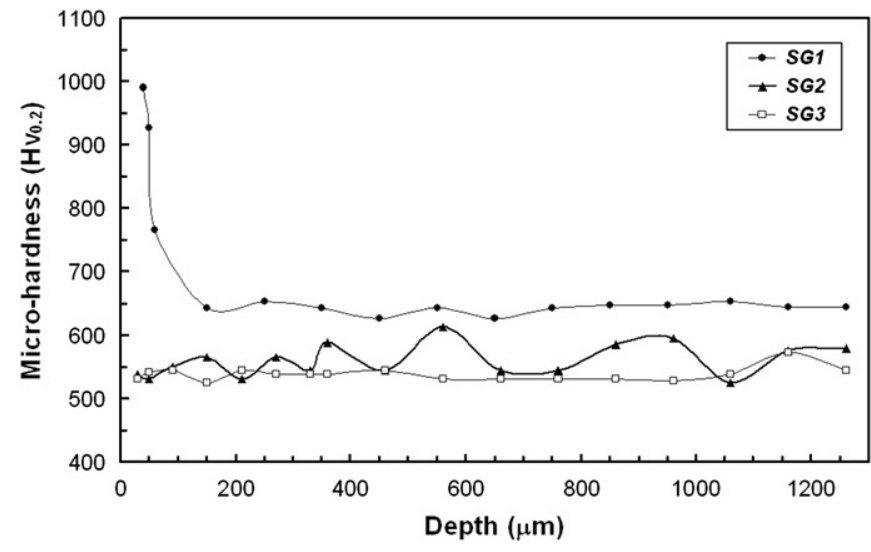

Fig. 1. Micro-hardness evolution inward from the die radius surface to $1.3 \mathrm{~mm}$ in depth, for the three steel grades.

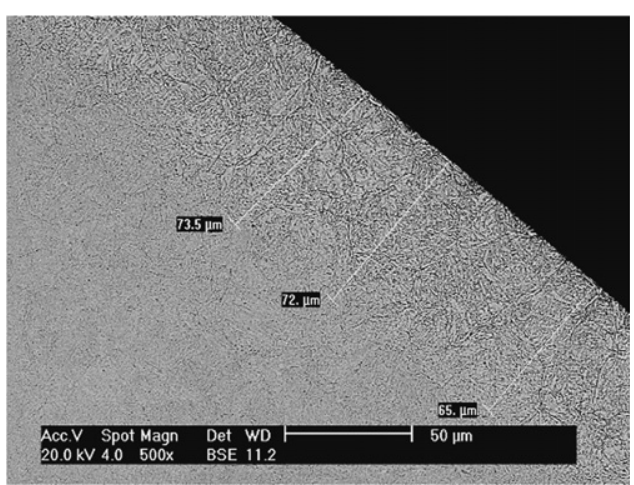

Fig. 2. SEM cross-section observation of the nitrided layer on SG1 die radius.

die radius was nitrided by an ionic process, resulting in an increase in its initial hardness from $653 \pm 8$ to $995 \mathrm{HV}_{0.2}$ (Fig. 1). The thickness of the nitrided layer is around $70 \mu \mathrm{m}$ (Fig. 2).

Steel grade 2 (SG2)

The composition of the second tool steel grade, detailed in Table 1 , is similar to a 60CrMoTiV16 alloy steel. This new grade is characterized by high hardness $\left(561 \pm 25 \mathrm{HV}_{0.2}\right)$, good resilience and good wear resistance. Its microstructure is globally martensitic, and exhibits two kinds of precipitates: the first population is large polyhedral precipitates rich in titanium, tungsten and silicon (Fig. 3), and the second is fine and spherical precipitates of a few hundreds of nanometers. By measuring its micro-hardness inward from the surface to a $1 \mathrm{~mm}$ depth, one can observe a cyclic fluctuation of the hardness around the mean value, between 530 and $610 \mathrm{HV}_{0.2}$ (Fig. 1). This fluctuation seems to be cyclic with a fairly constant space of $50 \mu \mathrm{m}$, and could be related to the large and hard precipitates of titanium which are homogeneously distributed in the matrix.

Steel grade 3 (SG3) 

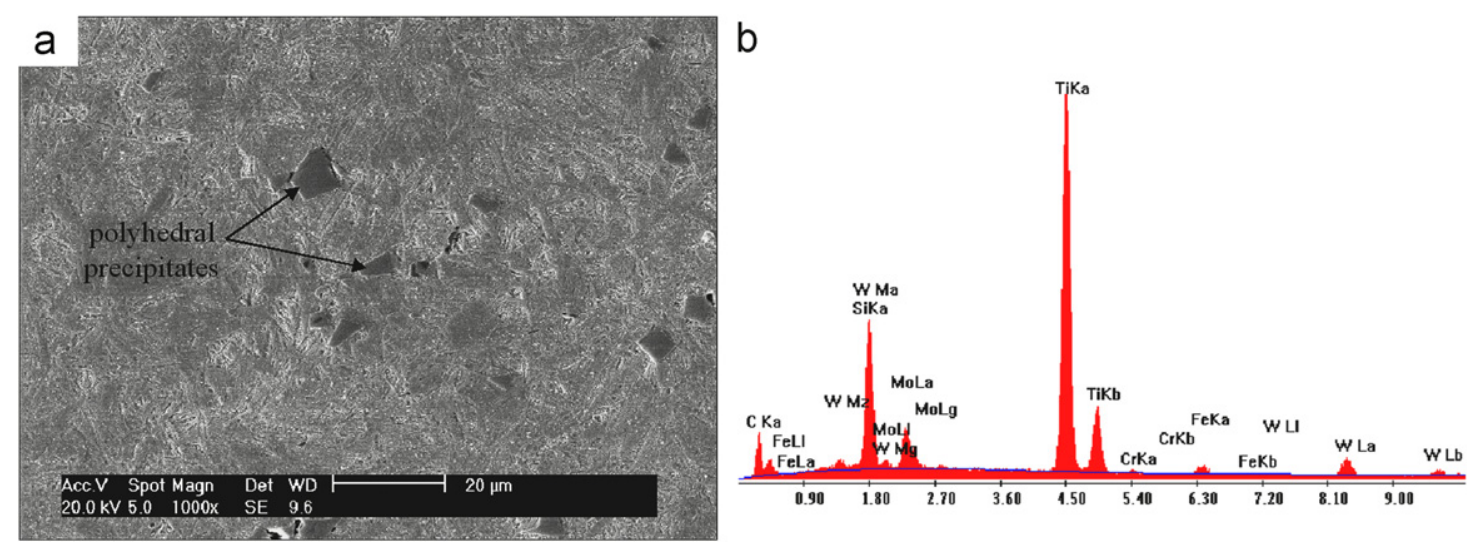

Fig. 3. SEM cross-section of SG2 die radius (a), showing large polyhedral precipitates rich in titanium (b).

Table 2

Chemical composition of the Usibor $1500 \mathrm{P}^{\mathbb{B}}$ steel [12].

\begin{tabular}{lllllll}
\hline Element & $\mathrm{C}$ & $\mathrm{Si}$ & $\mathrm{Mn}$ & $\mathrm{Cr}$ & $\mathrm{Al}-\mathrm{Ti}$ & $\mathrm{B}$ \\
\hline weight \% & $0.2-0.25$ & $0.15-0.35$ & $1.1-1.4$ & $0.15-0.30$ & $0.02-0.06$ & $0.002-0.004$ \\
\hline
\end{tabular}

Table 3

Mechanical properties of the Usibor $1500 \mathrm{P}^{\mathbb{R}}$ strip, at delivery (indicative values only) and after hot stamping according to best practices/typical values $\left(5-15 \min 900{ }^{\circ} \mathrm{C}-950{ }^{\circ} \mathrm{C}\right.$-type heat treatment, followed by quenching with perfectly cooled stamping tools-cooling rate $\geq 50^{\circ} \mathrm{C} / \mathrm{s}$ ) [12].

\begin{tabular}{lll}
\hline & At delivery & After hot stamping \\
\hline Yield strength, $R_{y}(\mathrm{MPa})$ & $350-550$ & 1100 \\
Ultimate Tensile strength, UTS $(\mathrm{MPa})$ & $500-700$ & 1500 \\
Elongation $e_{1}(\%)\left(L_{o}=80 \mathrm{~mm}, t h \leq 3 \mathrm{~mm}\right)$ & $\geq 10$ & 6 \\
\hline
\end{tabular}
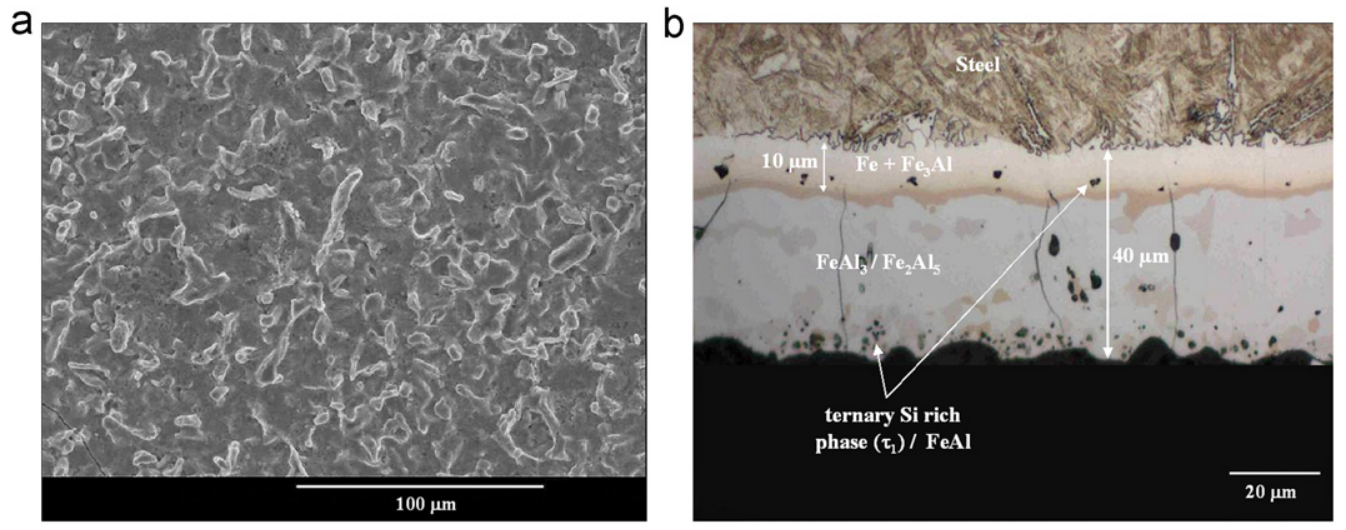

Fig. 4. SEM Surface (a) and cross-section (b) of the Al-Si strip coating.

The composition of the third tool grade is given in Table 1. Its microstructure is fully martensitic, and contains some fine and globular carbides, sizing around $1 \mu \mathrm{m}$, rich in iron, tungsten and silicon. Its initial hardness is $539 \pm 11 \mathrm{HV}_{0.2}$ (Fig. 1).

\subsection{Steel sheet}

The steel sheet grade is an Al-Si-coated press-hardened boronmanganese steel—Usibor $1500 \mathrm{P}^{\mathbb{R}}$-produced by ArcelorMittal. The composition and mechanical properties are given in Tables 2 and 3. The coils tested were $1 \mathrm{~mm}$ thick, $50 \mathrm{~mm}$ width, and $400 \mathrm{~m}$ length.

For the needs of the study, these coils were preliminarily prealloyed on the industrial heat-treatment line at Hugovogelsang in
Hagen, under the following conditions: $900{ }^{\circ} \mathrm{C}$ with $3.5 \mathrm{~m} / \mathrm{min}$. Microstructural observations of such pre-alloyed $\mathrm{Al}-\mathrm{Si}$ coating are illustrated in Fig. 4, in surface and cross-section. The coating presents sharp asperities on its surface (Fig. 4a). The cross-section indicates a thickness of $40 \mu \mathrm{m}$, composed of the superficial Fe-Al coating with intermetallic phases rich in $\mathrm{Si}$ (major phase in dark grey on the micrograph), and a thin $\left(\mathrm{Fe}+\mathrm{Fe}_{3} \mathrm{Al}\right)$ coating at the interface with the steel (Fig. 4b). This is in agreement with the literature [2]. Passing through several phase transformations (the first is at $575{ }^{\circ} \mathrm{C}$ ) and due to iron diffusion from the steel, an $\mathrm{Al}-\mathrm{Fe}$ binary intermetallic compound is formed. This phase of high melting point $\left(1020^{\circ} \mathrm{C}\right)$ prevents the coating layer from melting during the heat-treatment [2]. 


\section{Experimental procedure}

\subsection{Deep-drawing process simulator (DDPS)}

In order to reproduce tribological interactions between the strip and the tool in the drawing process, an experimental friction laboratory pilot (named Deep-Drawing Process Simulator) was developed [7,13]. The steel strip, unrolled directly from a coil, was heated by Joule effect with a resistance heating system (Fig. 5a). The correct alloying of the strip had been verified and thus, the heating module by joule effect of the DDPS served only to reheat the strip very rapidly at the target temperature, and not to alloy the coating during long isothermal steps. During the test, the temperature of the strip was controlled by a bi-chromatic pyrometer. A programmable logic control unit, monitoring the rolling-up and unrolling engines, was used to program repeated sliding cycles. When a prescribed temperature was reached, the heated zone of the strip was moved towards the tool, and slid on the die radius under normal loading. The strip was maintained in contact on the die radius by a special flat blank-holder during a few seconds, and then pulled through the working system by the rolling-up engine. The clearance between the strip and the blankholder was $0.2 \mathrm{~mm}$, so there was no direct friction between the strip and the blank-holder. At each cycle, a new, unworn section of the strip slid over the die radius (revolution surface), leading to its bending and unbending respectively at the entry and the exit of the die. Therefore, the strip has undergone a mechanical deformation. A previous study [7] has shown that the contact pressure was not only due to the pulling and restraining forces but also to the strip bending and unbending. This induces a nonuniform distribution of the pressure over the die radius, and the tighter the exit angle $\alpha$, the higher the pressure peak is at the entry of the radius.

For this study, the Deep-Drawing Process Simulator was adjusted to avoid an excessive abrasion of the die due to the cold part of the strip, in order to approach industrial conditions. For the same purpose, a mechanical system, called a "sheet release system", was added to heave up the-cold part of the strip. Consequently, only the hot part of the strip was in contact with the die radius (Fig. $5 b$ ).

\subsection{Tool geometry}

The tool geometry, displayed in Fig. 6a, is composed of a die radius $(\mathrm{Rm})$ of $6 \mathrm{~mm}$. To assess the spread of the wear damage on the tool surface, the die radius was divided into four sub-angular sections, forming a range of angular areas from $0^{\circ}$ to $65^{\circ}$, from the entry to the exit of the die-radius in contact with the strip (Fig. 6b). The initial arithmetic roughness $(R a)$ of the polished die-radius surface ranged from 0.14 to $0.25 \mu \mathrm{m}$, depending on the steel grade and the sub-angular section under consideration. One can note that the surface quality of the SG1 die radius was rougher at the die radius entry than at the exit, and that the
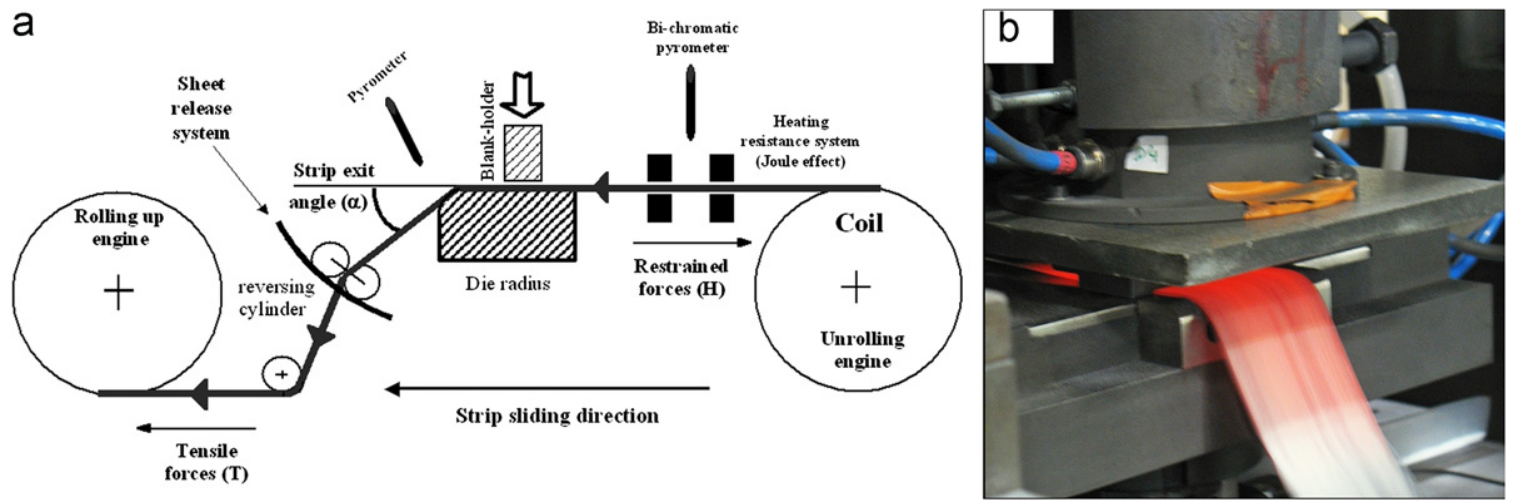

Fig. 5. Diagram of the Deep-Drawing Process Simulator "DDPS" (a), and detail of the hot strip sliding on the die radius in the working system (b).
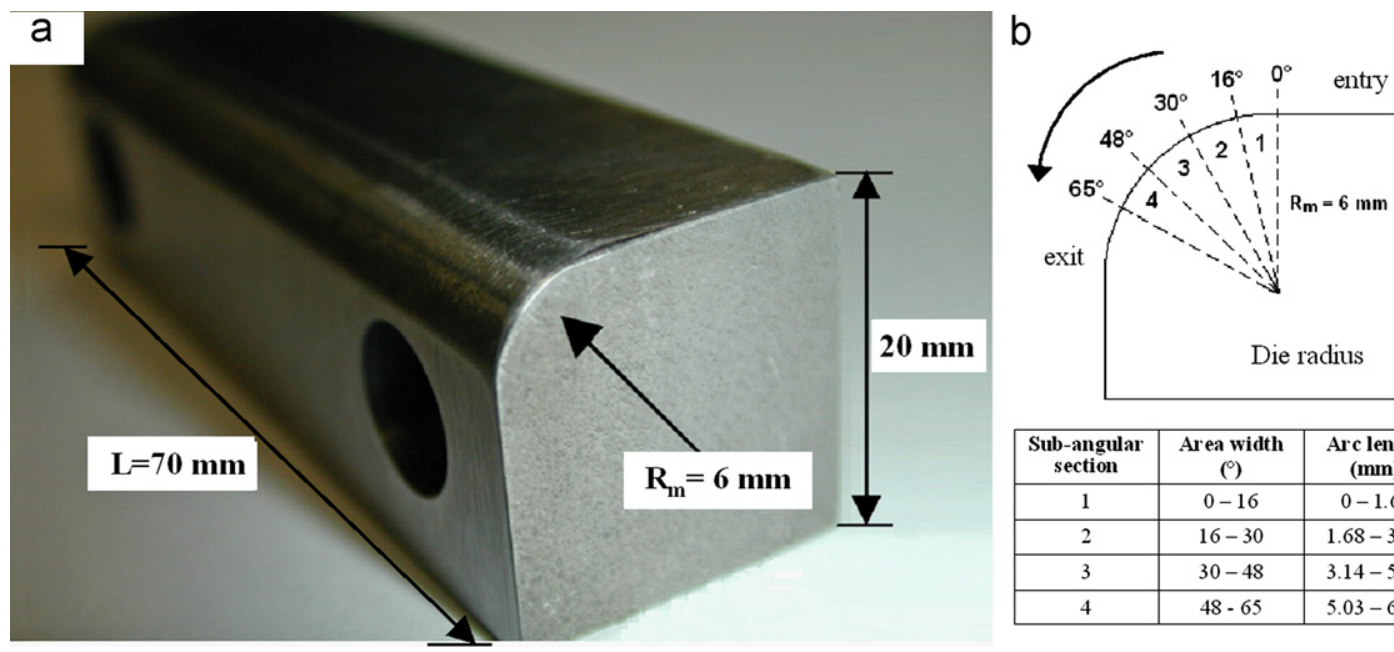

\begin{tabular}{|c|c|c|}
\hline $\begin{array}{c}\text { Sub-angular } \\
\text { section }\end{array}$ & $\begin{array}{c}\text { Area width } \\
\left({ }^{\circ}\right)\end{array}$ & $\begin{array}{c}\text { Arc length } \\
\text { (mm) }\end{array}$ \\
\hline 1 & $0-16$ & $0-1.68$ \\
\hline 2 & $16-30$ & $1.68-3.14$ \\
\hline 3 & $30-48$ & $3.14-5.03$ \\
\hline 4 & $48-65$ & $5.03-6.81$ \\
\hline
\end{tabular}

Fig. 6. Geometry and dimensions of the DDPS die radius sample (a), and definition of four sub-angular sections for the non-destructive investigations on the die radius cross-section (b). 
SG3 die radius exhibited the smoothest and most regular surface (Table 4).

\subsection{Tribological tests}

The pre-alloyed strip was heated up to $875^{\circ} \mathrm{C}$, and maintained at this temperature for $10 \mathrm{~s}$ before entering the working system. When the strip slides on the tool, its temperature, measured by a monochromatic pyrometer, was about $730^{\circ} \mathrm{C}$. The exit angle $(\alpha)$ of the strip was set at $80^{\circ}$, leading to a higher contact pressure at the entry of the die radius, and favoring the adhesion mechanism currently observed in the industrial process [7]. The other test parameters (mechanical adjustments of the DDPS) are given in Table 5.

Table 4

Arithmetical mean roughness $(R a, \mu \mathrm{m})$ measured on the die radii with a whitelight profilometer (Gaussian filter: cut-off $=0.8 \mathrm{~mm}$ ).

\begin{tabular}{llll}
\hline $\begin{array}{l}\text { Die radius } \\
\text { sub-angular section }\end{array}$ & SG1 & SG2 & SG3 \\
\hline 1 & $0.25 \pm 0.13$ & $0.15 \pm 0.03$ & $0.14 \pm 0.04$ \\
2 & $0.22 \pm 0.07$ & $0.18 \pm 0.02$ & $0.14 \pm 0.03$ \\
3 & $0.18 \pm 0.05$ & $0.20 \pm 0.03$ & $0.14 \pm 0.02$ \\
4 & $0.18 \pm 0.10$ & $0.19 \pm 0.04$ & $0.14 \pm 0.02$ \\
\hline
\end{tabular}

Table 5

Test parameters applied with the Deep-Drawing Process Simulator (DDPS).

\begin{tabular}{ll}
\hline Setting temperature $\left({ }^{\circ} \mathrm{C}\right)$ & 875 \\
Strip exit angle, $\alpha\left({ }^{\circ}\right)$ & 80 \\
Contact pressure, $P(\mathrm{MPa})[7]$ & $20-30$ \\
Sliding speed, $V(\mathrm{~mm} / \mathrm{s})$ & 250 \\
Sliding distance, $L(\mathrm{~mm})$ & 160 \\
Cycle* duration $(\mathrm{s})$ & 21 \\
\hline
\end{tabular}

* Strip heating + sliding
A first test campaign (test 1 ) was undertaken up to 5000 cycles with cycling interruptions at each 1000 cycles. A second trial (test 2) was conducted up to 2000 cycles, with shorter interruption intervals at 200, 500 and 1000 cycles. At each test interruption, non-destructive investigations were carried out in order to evaluate the degradation on the die-radius surface. The test conditions (strip temperature, sliding speed, sliding distance, tool materials and die radius geometry) were kept identical for both campaigns.

\subsection{Characterization of the wear damage}

When the tool sample was dismantled just after the test, a fine dust of non-adhesive particles was always clearly visible on the surface of the die radius (Fig. 7a). After cleaning of the sample in an ultrasonic bath, an adhesive transferred layer remained on the portion of the die radius in contact with the strip (Fig. 7b). Further detailed investigations revealed that the die radius was also affected locally by a loss of material.

Because of the cylindrical shape of the die radius, it is not straightforward to quantify wear loss and material transfer. A methodology was proposed and new damage criteria, based on profilometric measurements, were defined to assess the relative amount of adhesion and abrasion on the die radius surface [11]. On each sub-angular section, three profiles were measured along the longitudinal direction of the die radius, using a white-light confocal microscope. Three wear criteria were then calculated on the 2D straightened profiles, ignoring sub-angular section 4 (Fig. 6b), since the wear damage was negligible on this part of the die radius:

- The transfer wear area criterion, $S t_{m}=\sum_{p=1}^{9} S t_{t_{p}} / 9 L p$, represents the mean value of the area of the transfer layer $\left(S t_{t}\right.$, as defined in Fig. 8) measured on the 9 profiles acquired on sections 1-3;

- The material loss area criterion, $S u_{m}=\sum_{p=1}^{9} S u_{t_{p}} / 9 L p$, represents the mean value of the area of the material loss $\left(S u_{t}\right.$, as defined in Fig. 8);
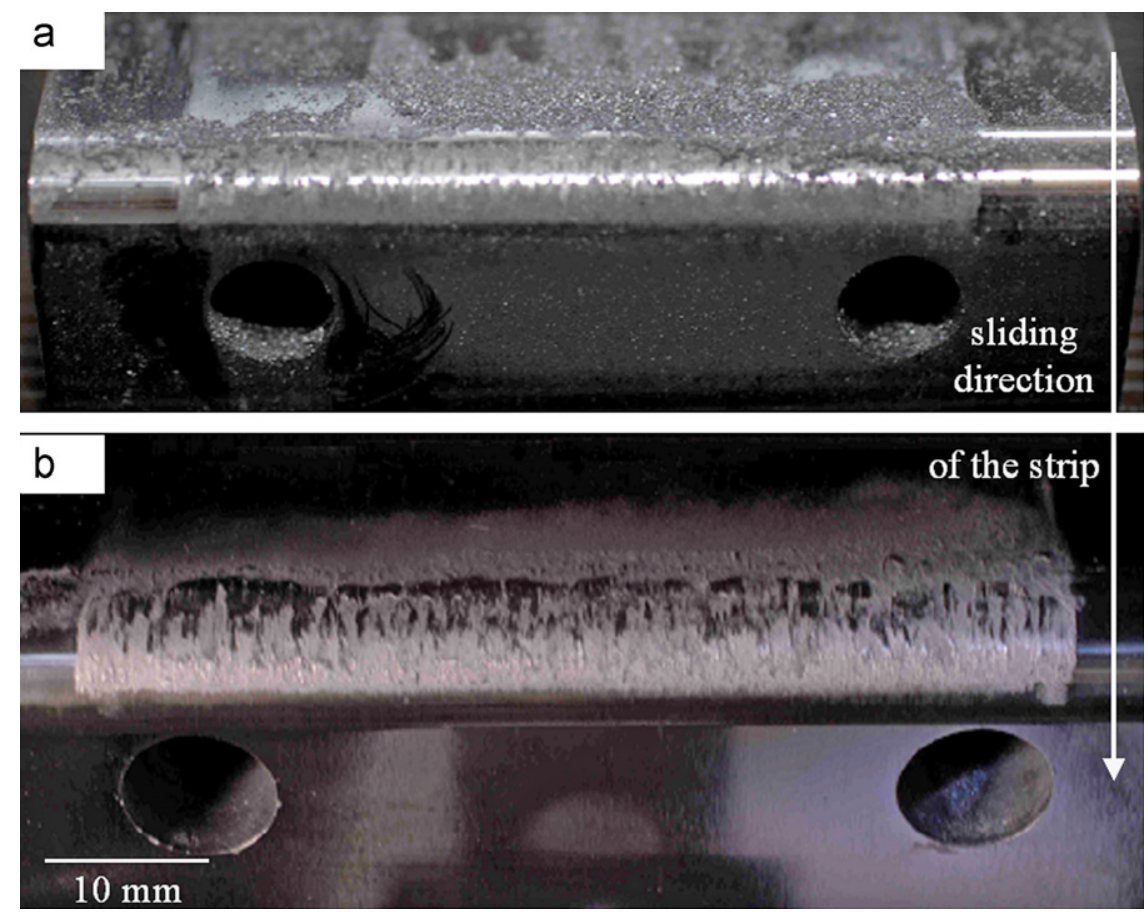

Fig. 7. Macro-observation of the die radius just after the 5000 cycles test, showing non-adhesive strip coating particles (a), and an adhesive transfer layer remaining after the cleaning of the die-radius surface (b). 


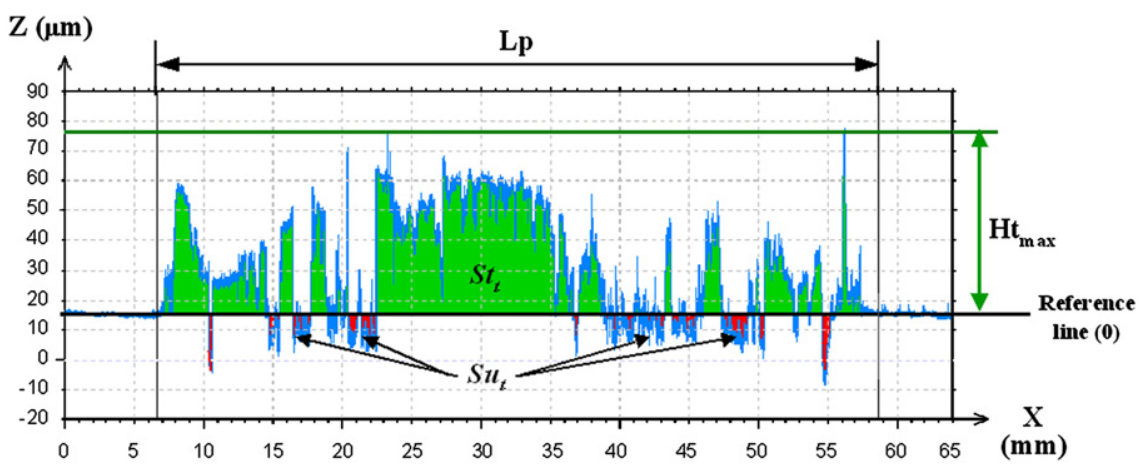

Fig. 8. Determination of the wear criteria on a straightened profile (the reference line is the mean plane of the unworn zone, and $L p$ is the length of the worn part on the die radius): transfer wear area $S t_{t}$ (total area in green, above the reference line), material loss area $S t_{u}$ (total area in red, below the reference line), and transfer regularity $\left(\operatorname{Tr}=S t_{t} \cdot H t_{\max } / L p\right)$.
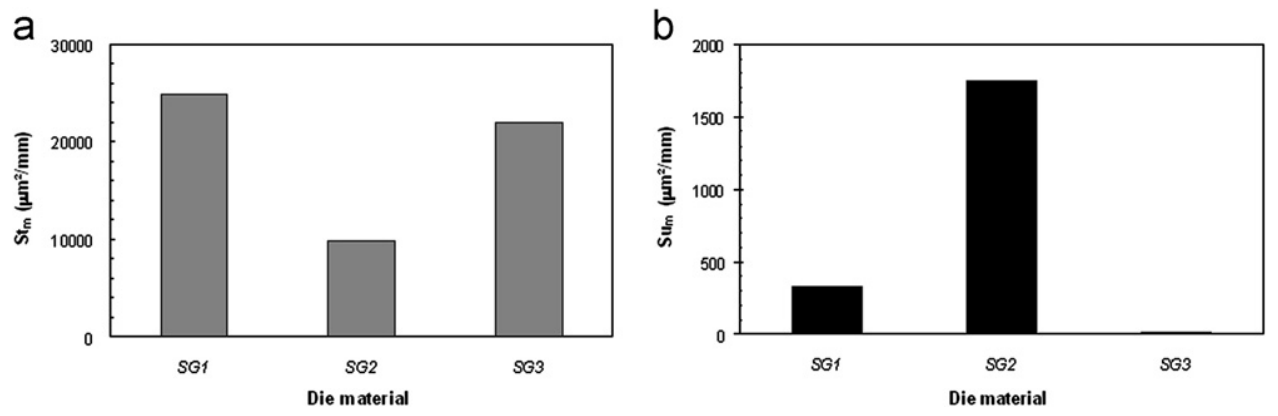

Fig. 9. Ranking of the three steel grades regarding their propensity to adhesion and abrasion, evaluated respectively by the transfer damage criterion $S t_{m}$ (a) and the material loss criterion $\mathrm{Su}_{m}$ (b) after 5000 cycles (test 1 ).

- The transfer wear regularity criterion, $\operatorname{Tr}_{m}=\sum_{p=1}^{9} \operatorname{Tr}_{p} / 9$, represents the mean value of the regularity of the transfer layer ( $T r$, as defined in Fig. 8).

To complete the profilometric measurements, the surface of the die radius was observed by scanning electron microscopy (SEM), at each cycling interruption. After 5000 cycles, all the die radii were cut in order to prepare transverse cross-sections. The cross-section samples were observed by SEM to investigate the sub-surface damage along the die radius. In addition, the chemical composition of wear elements was analyzed by energy dispersive spectroscopy (EDS).

\section{Results}

\subsection{Wear damage and ranking of die materials}

Two kinds of surface degradation can be identified on the die radius:

- a compact adhesive layer and

- a localized material loss.

The first wear damage, observed for all steel grades, is an adhesive mechanism at high temperature of fine particles resulting from attrition of the superficial part of the Al-Si coating. EDS analysis reveals that this compact adhesive layer contains iron, aluminum and silicon. If this attrition comes from shear stresses, one can conclude that the strip bending in the working system leads to high pressures on the die radius at the entry of the contact, favoring the intergranular cracking and rupture of the coating. In addition, the rough surface of the coating could amplify this mechanism. The three steel grades tested on the
DDPS can be ranked in term of their resistance to adhesion, evaluated through the transfer damage criterion $S t_{m}$. After 5000 cycles, the material transfer is almost equivalent on SG1 and SG3, and much less on SG2 (Fig. 9a).

The second wear mechanism is a material loss localized on some parts of the die radius. This phenomenon is less significant than the adhesive wear, the quantities of material loss measured on the die radius being about 10-3000 times lower than the material transfer. The abrasive wear, evaluated by the material loss criterion $\left(\mathrm{Su}_{m}\right)$, concerns more particularly SG2, whereas it is quasi-negligible on SG3 (Fig. 9b).

For this study, the wear criteria were calculated only for the sub-angular sections $1-3$, because sub-angular section 4 presented no significant damage, regardless of the steel grade. It must be recalled that $S t_{m}$ and $S u_{m}$ are average values calculated from 9 profile measurements, and for the sake of simplicity, the standard deviations will not be indicated in the following results. In fact, the wear is not uniformly distributed over the die radius, because of the strip exit angle and the resulting local pressure spread [7]. As the damage (especially the adhesive wear) is highly localized at the boundary between sub-angular sections 1 and 2 on the die radius, the standard deviations are not representative of the results trend. A study on the reproducibility and reliability of the damage criteria is presented and discussed in [11].

\subsection{Adhesion behavior of die materials}

Considering the results of the two test campaigns carried out on the DDPS pilot, the behavior of SG1 differs from the two other steel grades regarding the resistance to adhesion (Fig. 10). On SG1, the transfer damage criterion $S t_{m}$ reaches an asymptotic value after 2000 cycles for the test campaign conducted up to 5000 cycles (test 1 ), whereas for the second trial with shorter interruption intervals up to 2000 cycles (test 2), St $t_{m}$ stabilizes 
after only 500 cycles. Thus, it can be claimed that the asymptotic level is reached as soon as the adhesive transfer is effective on the die radius. One can surmise that this number of cycles may even have been lower if the experiments had been interrupted earlier, therefore better evaluating the transient regime between the initial condition of the tool and the well established adhesive regime. For both SG2 and SG3 materials, $S t_{m}$ never stabilizes, and presents cyclic fluctuations. SG3 is however characterized by a maximal $S t_{m}$ value close to SG1. SG2 presents lower average $S t_{m}$ values, indicating that its adhesion mass transfer is less significant on this tool. It should be noted that for all three steel grades, the maximal amount of mass transfer is reached in the first few hundred cycles. For information purposes, the maximal thickness of the transferred layer is about $120 \mu \mathrm{m}$ in height on SG1 and SG3 (with, locally, some higher peaks of up to $200 \mu \mathrm{m}$ ), whereas the maximal thickness is $70 \mu \mathrm{m}$ for SG2.

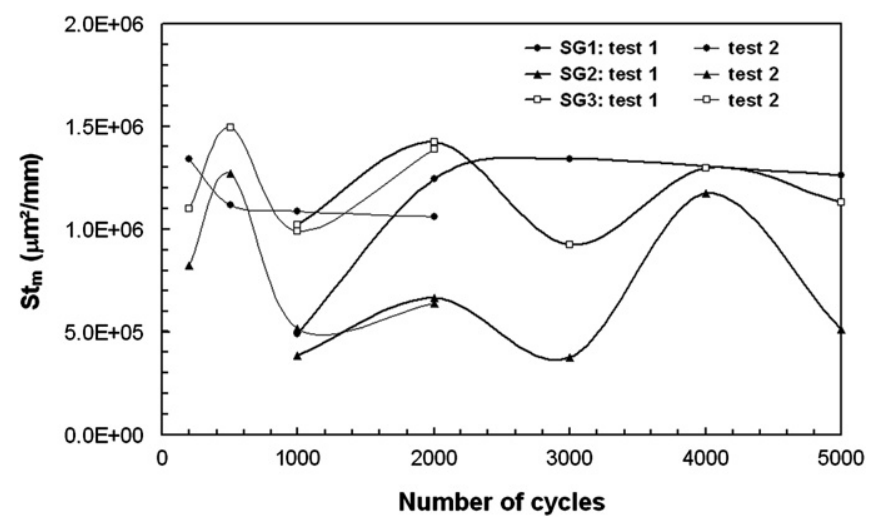

Fig. 10. Evolution with the number of cycles of the transfer damage $S t_{m}$ criterion, for the three steel grades and both cycling tests.

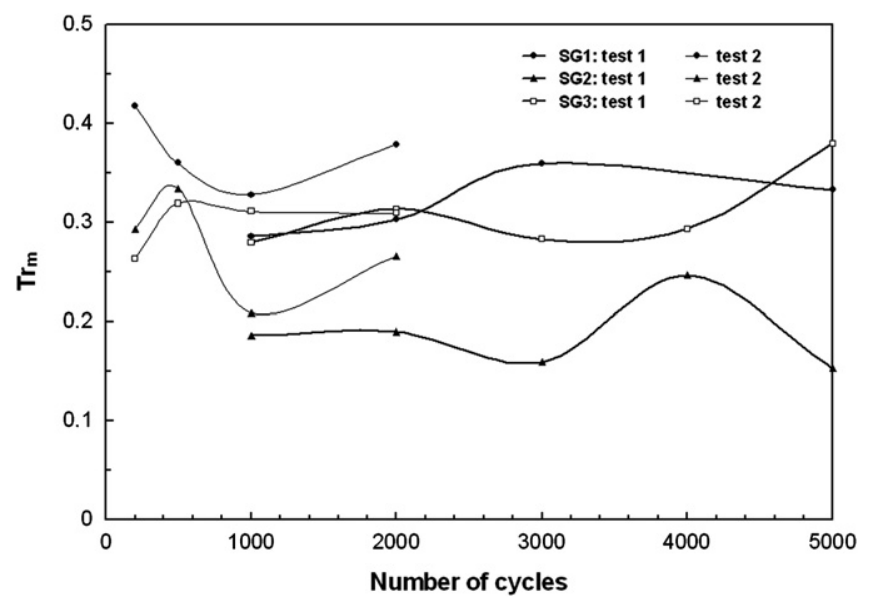

Fig. 11. Evolution with the number of cycles of the transfer regularity $T r_{m}$ criterion, for the three steel grades and both cycling tests.

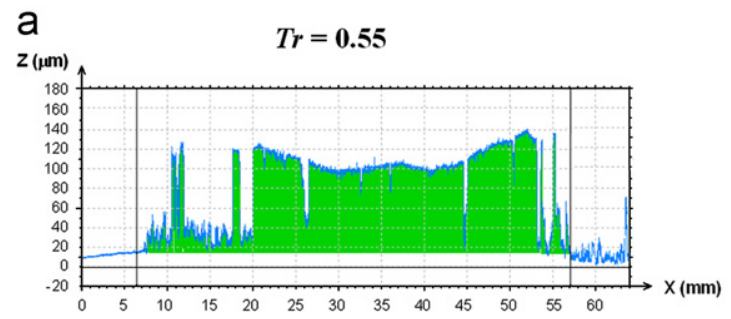

It is noticeable that the maximal values of the three steel grades are quite similar for the two test campaigns (Fig. 10). Except at 1000 cycles for SG1 (a result linked to its transient behavior at the beginning of the cycling), all points corresponding to an equivalent number of cycles are practically identical for both tests. In addition, SG2 and SG3 present the same cyclical trend in both tests. It should thus be emphasized that a particularly high reproducibility is found between the two test campaigns, indicating the high reliability of the DDPS pilot [11].

The regularity criterion of the transfer layer $\left(\operatorname{Tr}_{m}\right)$, describing both its compactness and its uniformity [11], ranges globally between 0.15 and 0.42 (Fig. 11). It must be recalled that $T r_{m}$ values result from an averaging on several profile measurements, and that much higher values were measured locally on some tools. Especially for SG1, $\operatorname{Tr}$ is close to 0.6 at the entry of the die radius where the transfer layer is very compact (Fig. 12a).

One can observe in Fig. 11 that $T r_{m}$ follows a cyclical evolution very similar to $S t_{m}$. SG1 presents the highest values, which vary from 0.29 to 0.42 depending on the number of cycles. These values can be understood as reflecting a relatively highly compacted and uniform morphology of the adhesive transferred layer on the die radius. SG3 is characterized by the same order of magnitude of $T r_{m}$, ranging from 0.26 to 0.38 . For SG2, $T r_{m}$ values, ranging between 0.15 and 0.33 , are significantly lower than for two others steel grades (as previously noted for $S t_{m}$ criterion). This indicates that the transfer layer presents a more irregular and fragmented morphology, as can also be observed from the profile measurements (Fig. 12b).

\subsection{Abrasive wear behavior of die materials}

As previously mentioned, abrasive wear is a minor phenomenon. Nevertheless, the loss of material damage criterion $\left(\mathrm{Su}_{m}\right)$ reveals significantly higher values for SG2 (Figs. 13 and 14),

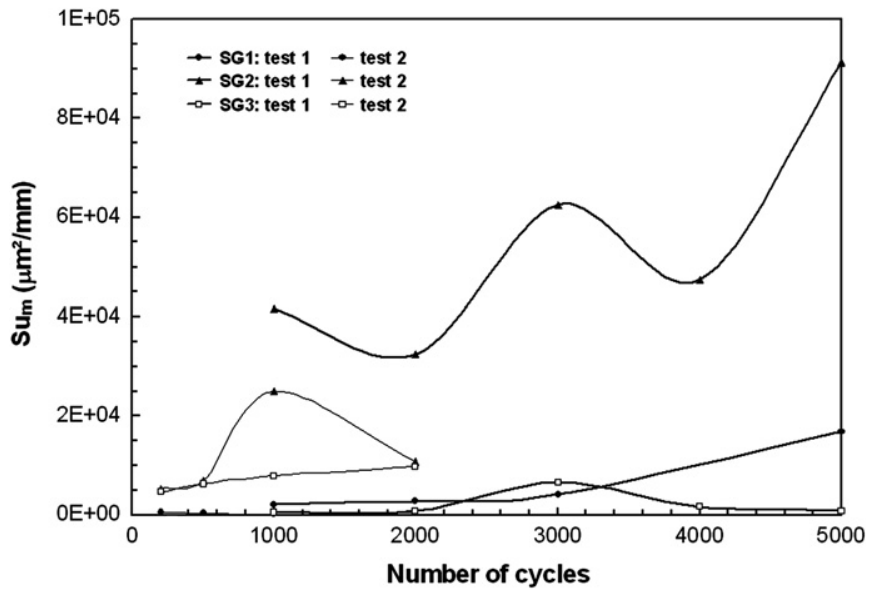

Fig. 13. Evolution with the number of cycles of the material loss criterion $\left(S u_{m}\right)$ for the three steel grades and both cycling tests.

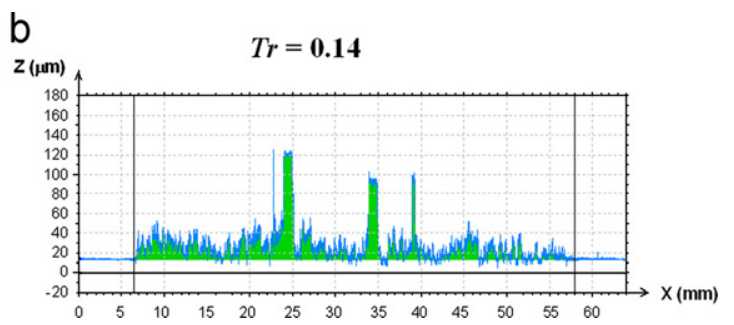

Fig. 12. Surface profiles showing different morphologies and regularity parameter $(\operatorname{Tr})$ for the adhesive transferred layer, at the entry of the die radius after 5000 cycles: compact and homogeneous layer $(\operatorname{Tr}=0.55)$ for SG1 (a); irregular and fragmented layer $(\operatorname{Tr}=0.14)$ for SG2 (b). 


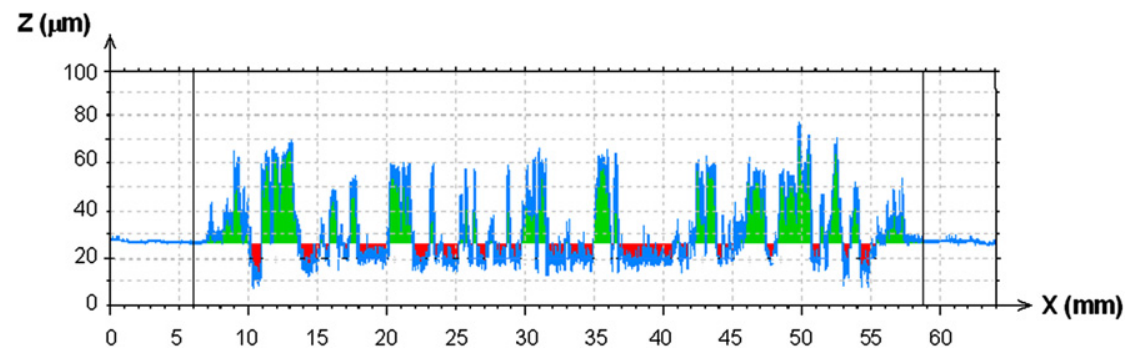

Fig. 14. Localized loss of material observed after 3000 cycles on the die radius (SG2).

SG1

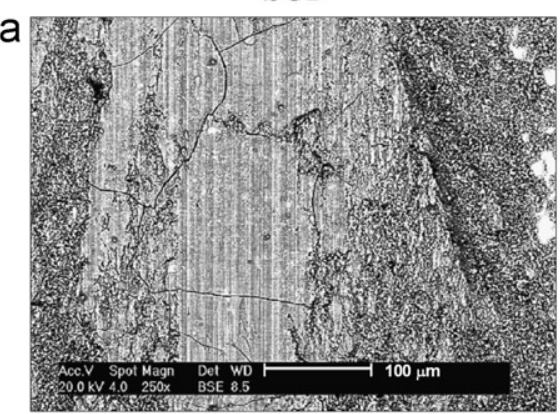

\section{b}

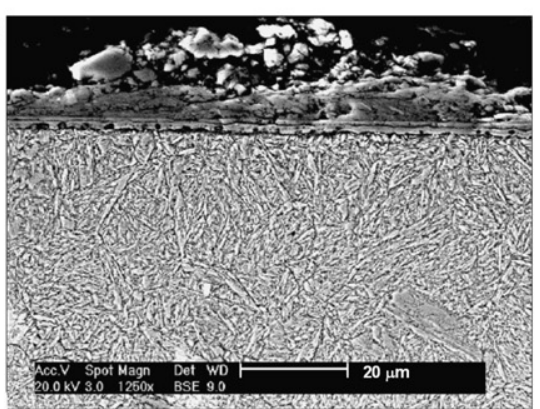

$S G 2$
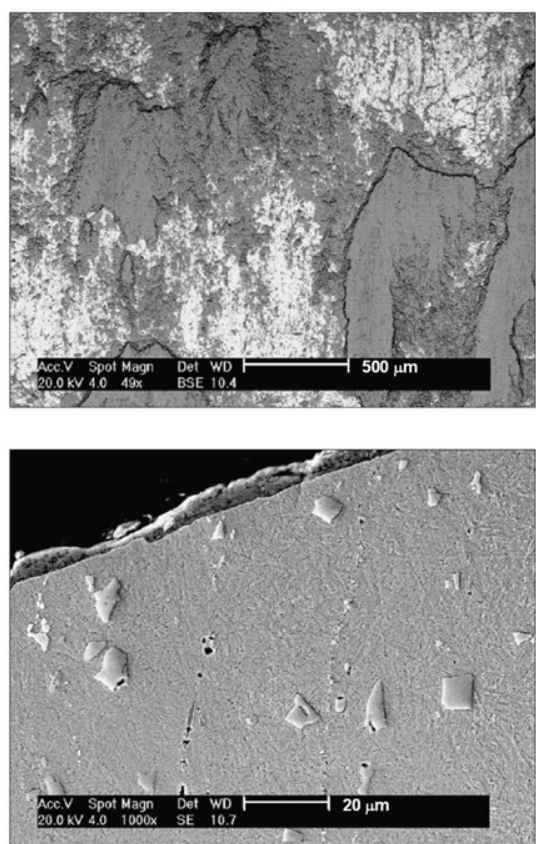

SG3
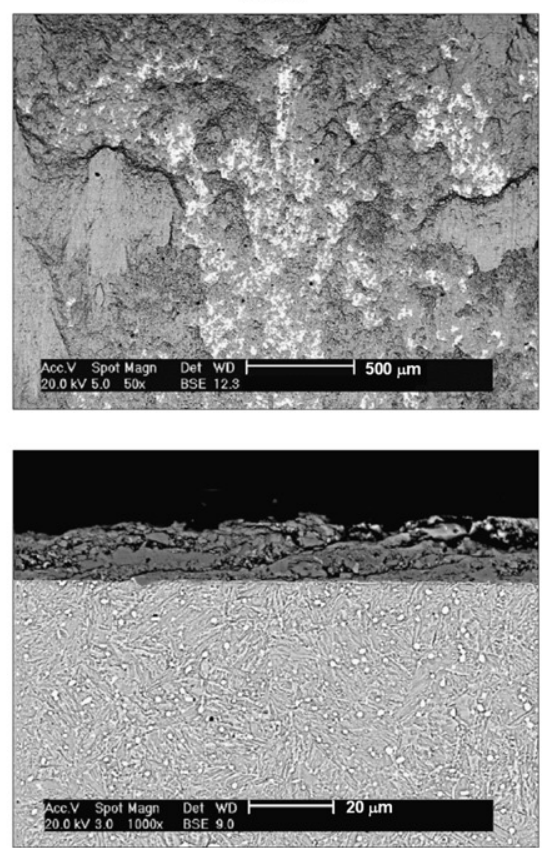

Fig. 15. SEM observations showing the transferred layer on SG1, SG2 and SG3: (a) back-scattered images of the die radius surface after 2000 cycles (the transferred layer is in grey, the steel in white) and (b) transverse cross-sections after 5000 cycles.

especially at a high number of cycles (beyond 2000 cycles). The maximal depth of material loss can then reach $30 \mu \mathrm{m}$ on highly localized areas. A fluctuating evolution of $\mathrm{Su}_{m}$ is still observed for SG2 and SG3, while for SG1, the loss of material increases slightly with the increasing number of cycles. For SG1 and SG2, the maximal value is measured after 5000 cycles, contrary to SG3 for which the abrasive wear is very low at 5000 cycles (Fig. 13). It can thus be concluded that SG2 has the highest propensity for loss of material. However, this result must be moderated by the fact that for SG1 and SG3, a possible loss of material could be hidden locally because of the large amount of transferred particles on the die radius.

\subsection{Microstructural observation of die materials}

Regardless of which steel grade is examined, SEM micrographs shown in Fig. 15 reveal the presence of a transferred layer, which is clearly visible at the entry of the die radius (i.e. on sub-angular sections 1 and 2). EDS analysis indicates that it is constituted of aluminum, silicon and iron, proving that this layer is formed by particles coming from the coating of the strip. The transferred layer is more or less compacted depending on the steel grade (Fig. 15a). However, some superficial cracks are observed, especially on SG1. These cracks are probably formed during cooling at the end of the experiment. On SG1, the transfer layer presents a glazed aspect on large areas, and abrasive scars in the sliding direction of the strip. The steel surface is partially visible, especially on SG2 where the transferred particles, which are not completely agglomerated, lead to a rougher surface. SEM crosssections highlight that the thickness of the transfer layer is thinner and less uniform on SG2 (Fig. 15b). SG3 is characterized by a substantial transfer layer at the entry of the die radius, and even on the sub-angular sections 3 and 4 . This layer has a thickness varying from 10 to $30 \mu \mathrm{m}$, and presents a foliated morphology with successive strata related to the cyclical nature of the test (Fig. 16).

On the nitrided SG1 tool, the cracks initiated at the surface lead to the fracture of the nitriding layer from the sub-angular section 3 to the exit of the die radius, but no shear plastic deformation of the sub-surface substrate is observed (Fig. 17).

SEM cross-sections of SG2 and SG3 reveal that the die radius surface has undergone a shear plastic deformation, from subangular section 2 to the die radius exit (Fig. 18). The martensitic laths are stretched in the sliding direction of the strip on about 10 to $20 \mu \mathrm{m}$ in depth. In addition, some precipitates are observed in this plastic flow area. In the case of the SG2 tool, in addition to the very small precipitates (initial state), precipitates sizing between 2 and $3 \mu \mathrm{m}$ are found in the deformed sub-surface (Fig. 18a). These "new" precipitates probably result from the fragmentation of the large titanium precipitates of the steel under the cyclic plastic shearing. The plastic deformation occurs whether the transferred layer is present or not, and sometimes induces some 


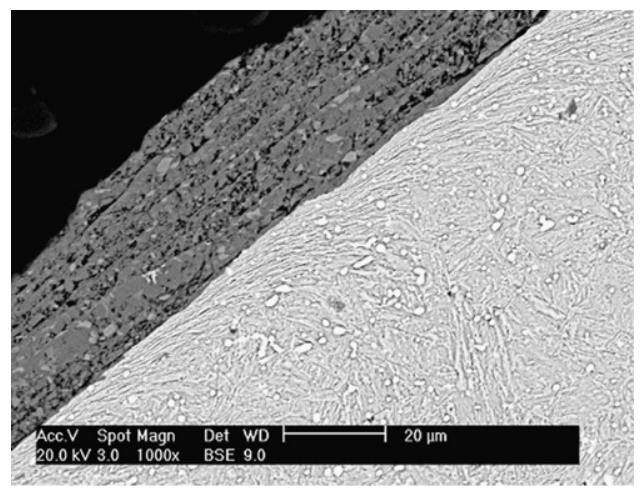

Fig. 16. Layered structure of the thick transferred layer on SG3 at the die radius exit.

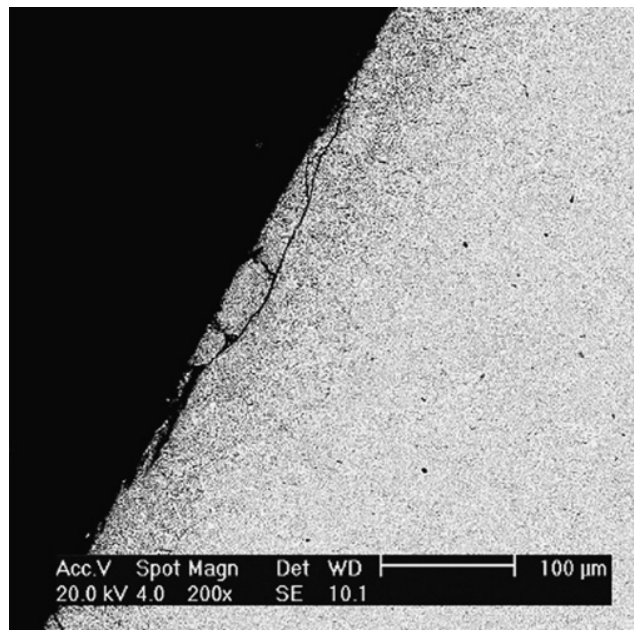

Fig. 17. SEM cross-section of SG1 tool, showing the surface cracking at the dieradius exit (b). micro-cracking parallel to the surface of the die radius (Fig. 19). Towards the die radius exit, the plastic flow is amplified and may lead to the formation of wear particles (Fig. 19b).

\section{Discussion}

Considering the profilometric results, only a few hundred cycles are necessary to obtain a substantial transfer layer on the die radii, whereas the abrasion mechanism needs more than 1000 cycles to be observed. The transfer layer is built on the surface of the tool by successive deposition of Al-Si powder at each cycle of sliding strip. For each tool grade, the maximal thickness of this layer is reached after 500 cycles. In addition, two kinds of behavior can be distinguished depending on the hardness of the die radius surface. For the nitrided surface (SG1), the transfer wear criterion $\left(S t_{m}\right)$ rapidly reaches an asymptotic value, and then remains unchanged (stable regime). For non-nitrided tools (SG2 and SG3), this value never stabilizes, and presents a cyclic evolution versus the number of cycles. These results are confirmed by the microstructural observations.

Experimentally, a transfer thickness higher than $200 \mu \mathrm{m}$ has never been measured on the die radii. This can be explained by the design of our experimental device (DDPS) and its "mechanical signature" at the contact, as described in Section 3.1. The non uniform pressure distribution over the die radius, as well as the maximal pressure at the entry of the contact, contribute to limit the thickness of the transfer layer. When the thickness of the layer is too high, only a small amount of the upper layer of the transfer layer is partially removed.

The SG1 die radius, because of the nitrided surface, presents the highest superficial hardness and the roughest surface quality, especially at the die-radius entry. As demonstrated above, its interaction with the steel strip leads to a considerable metallic transfer layer onto the die radius surface, particularly thick and compact at the entry. Indeed, the rough interface of the steel probably favors the mechanical anchoring of the particles emitted

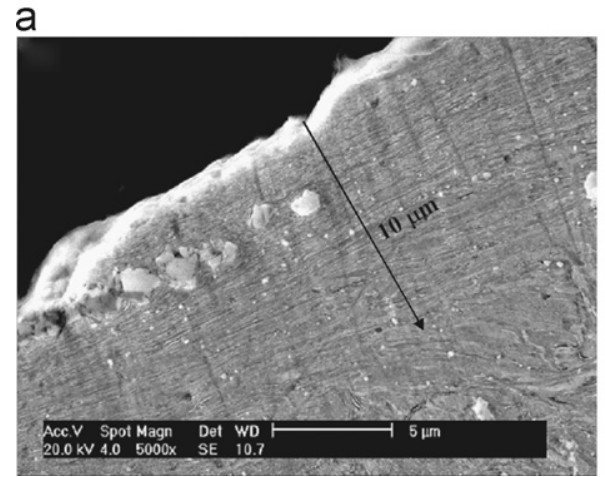

b

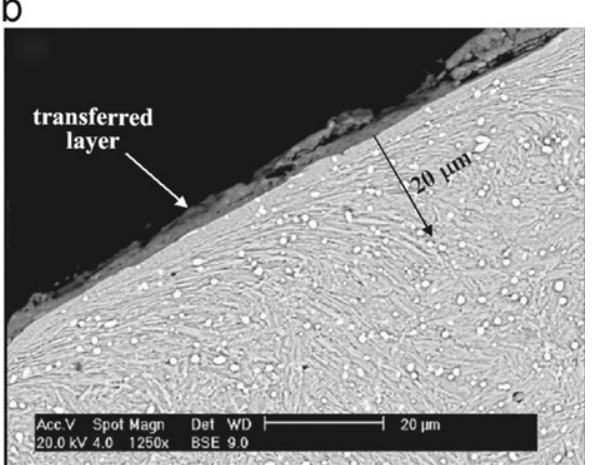

Fig. 18. Plastic deformation of martensitic laths on SG2 (a) and SG3 (b), at the die radius exit.

a

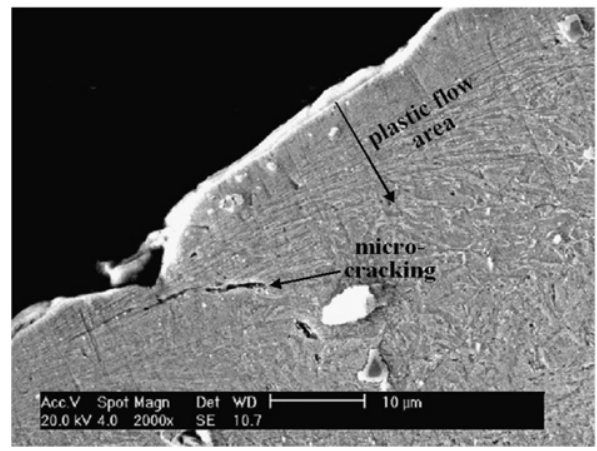

b

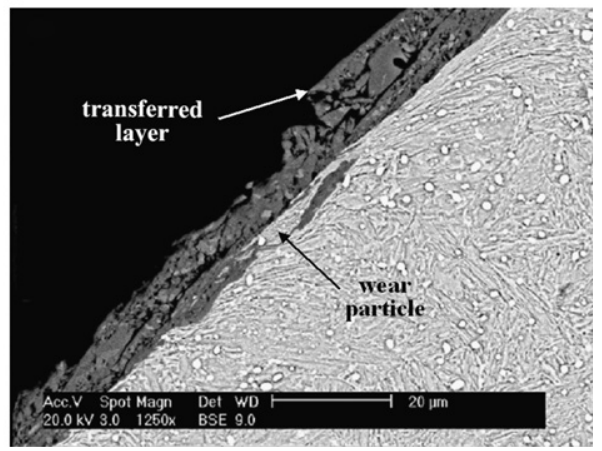

Fig. 19. Formation of wear particles under plastic deformation of the sub-surface, at the exit of SG2 (a) and SG3 (b) die radii. 
from the coating layer during the repeated sliding of the strip. The transfer damage $\left(S t_{m}\right)$ and regularity criteria $\left(\operatorname{Tr}_{m}\right)$ indicate that this agglomerated transfer layer remains rather constant and compact during the test in the stabilized regime (Figs. 9 and 10). The steel sub-substrate does not exhibit any appreciable plastic shear deformation, due to its high superficial hardness, probably coupled with the protective effect of the compacted transfer layer. Only after 5000 cycles, the abrasive wear of SG1 becomes more pronounced than SG3 (Fig. 13). This could be explained by a fatigue damage progressing in the very hard nitrided surface after a large number of cycles, which thus leads to cracking and spalling of the nitrided layer.

The SG2 die radius presents a smoother surface and a lower hardness, except where the large, hard titanium precipitates are located. This gives rise to a much smaller and unstable transferred layer, and greater abrasive wear (Figs. 9, 10, and 13). This behavior could be attributed to the plastic deformation of the sub-surface, which contributes to the shearing of the transfer layer. Consequently, the transfer layer is partially and cyclically removed on the die-radius surface during the test. Plastic deformation of the steel sub-surface is caused by shearing stresses between the strip and the die radius. A same phenomenon was observed on the X38CrMoV5 tool steel submitted to tribological solicitations [14]: by cumulative plastic shearing, when the critical shear ductility of the steel is achieved, microrupturing occurs and wear particles are ejected from the contact. In the case of SG2 tool, the hard titanium precipitates close to the die radius surface are driven by the plastic shearing deformation flow of the sub-surface, and are then fragmented. The polyhedral shape of these precipitates could also contribute to favoring their fragmentation. Coupled with the plastic deformation of the subsurface, these small titanium carbides lead to the emission of wear debris, which amplify the abrasion mechanism during the sliding of the strip, especially at the exit of the die radius.

The SG3 die radius exhibits a significant transfer layer with a layered structure, corresponding to its cyclical formation. The low and uniform hardness of this steel leads also to a plastic deformation of the die radius sub-surface, within a depth close to that found in SG2. We can consider that the matrix hardnesses of SG2 and SG3 are rather similar, which could thus explain why the depths of the plastic deformation are equivalent. Nevertheless, the abrasive wear is very limited, because the precipitates are smaller and rounder than in SG2.

With our device configuration and investigated parameters, the SG3 tool presents the best compromise between abrasive and adhesive wear. However, it should be emphasized that the DDPS pilot is not necessarily representative of the hot stamping industrial process. But, it could be assumed that the wear behavior of these steel grades may be similar with the DDPS pilot and our experimental device.

\section{Conclusion}

Cycling tests were performed using a Deep Drawing Process Simulator (DDPS), to investigate the wear behavior of three different tool steel grades during the sliding at high temperature of a pre-alloyed Al-Si-coated press-hardened high-strength steel (Usibor $1500 \mathrm{P}^{\circledR}$ ). The DDPS, upgraded for this study, is a convenient laboratory pilot to reproduce the actual conditions of tribological interactions between the tool and the sheet metal in a hot sheet-metal-forming process.

In this work, the major damage observed on the die radii is a material transfer mechanism, resulting from the adhesion of the strip-coating particles during the hot-strip sliding. Abrasive wear appears as a minor phenomenon. The surface damage exhibits a rapid kinetic, only a few hundred cycles being necessary to obtain a significant transfer layer on the die radius.

The three grades of steel investigated present different adhesive and abrasive behaviors. On the nitrided SG1 die radius, a compact and glazed transfer layer forms and stabilizes rapidly from 500 cycles onwards. SG2 generates a smaller and less continuous transfer layer, but seems more degraded by loss of material, which could be explained by the presence of hard and large titanium precipitates near its surface. SG3 is sensitive to material transfer, even in the dieradius exit, and produces less abrasive wear linked to the smaller size of the hard precipitates included in the matrix. Like SG2, the evolution of the transferred layer, formed by particles that are not totally agglomerated, is cyclic. This cyclical evolution has been by a cumulated cyclic plastic deformation of the sub-surface of the substrate. The smoothest steel grades (SG2 and SG3) exhibit a strong plastic deformation in the sub-surface, especially at the die radius exit, whereas for SG1, the plastic deformation is hindered by the nitriding layer on the tool surface.

With this upgraded device and the associated methodology, we have been able to classify the adhesive wear of tool material intended for hot stamping. The results of this study have highlighted that some modification in the formulation of the tool material could improve their adhesion and abrasion resistance in the hot sheet-metal-forming process with Usibor $1500 \mathrm{P}^{\circledR}$ coated with $\mathrm{Al}-\mathrm{Si}$, GA coating or others.

\section{Acknowledgments}

The authors would like to thank V. Lucin and S. Tovar (from ICA-Albi) for their technical contribution, and also D. Viale (from Industeel-Creusot) for its tool product technical expertise and its contribution to the study.

\section{References}

[1] P. Hein, J. Wilsius, Status and innovation trends in hot stamping of Usibor1500P, Steel Research International 9 (2008) 85-91.

[2] F. Borsetto, A. Ghiotti, S. Bruschi, Investigation of the high strength steel Al-Si coating during hot stamping operations, Key Engineering Materials 410-411 (2009) 289-296.

[3] J. Hardell, B. Prakash, High-temperature friction and wear behavior of different tool steels during sliding against $\mathrm{Al}-\mathrm{Si}$ coated high-strength steel, Tribology International 41 (2008) 663-671.

[4] J. Hardell, E. Kassfeldt, B. Prakash, Friction and wear behavior of high strength boron steel at elevated temperatures of up to $800^{\circ} \mathrm{C}$, Wear 264 (2008) 788-799.

[5] J. Hardell, B. Prakash, Tribological performance of surface engineered tool steel at elevated temperatures, International Journal of Refractory Metals and Hard Materials 28 (2010) 106-114.

[6] J. Kondratiuk, P. Kuhn, Tribological investigation on friction and wear behavior of coatings for hot sheet metal forming, Wear 270 (11-12) (2011) 839-849.

[7] C. Boher, D. Attaf, L. Penazzi, C. Levaillant, Wear behavior on the radius portion of a die in deep-drawing: identification, localisation and evolution of the surface damage, Wear 259 (2005) 1097-1108.

[8] P. Groche, G. Nitzsche, A. Elsen, Adhesive wear in deep drawing of aluminum sheets, CIRP Annals-Manufcturing Technology 57 (2008) 295-298.

[9] P. Groche, G. Nitzsche, Influence of temperature of initiation of adhesive with respect to deep-drawing of aluminum alloys, Journal of Materials Processing Technology 191 (2007) 314-316.

[10] E. Kassfeldt, J. Lundmark, Tribological properties of hardened high strength boron steel at combined rolling and sliding condition, Wear 267 (2009) 2287-2293.

[11] S. Le Roux, C. Boher, L. Penazzi, C. Dessain, B. Tavernier, A methodology and new criteria to qualify and quantify the adhesive and abrasive wear damage on a die radius using white light profilometry, Tribology International 52 (2012) 40-49.

[12] J. Wilsius, P. Kein, R. Kefferstein, in: M. Geiger, M. Merklein (Eds.), Status and future trends of hot stamping of Usibor 1500P, 7, Tagunsband zum 1, Erlanger Workshop Wearmblechumformung, Erlangen (Germany), 2006, pp. 83-101, November.

[13] C. Dessain, Ph. Hein, J. Wilsius, L. Penazzi, C. Boher, J. Weikerts, Experimental investigation of friction and wear in hot stamping of USIBOR 1500P, in: Proceedigns of the 1st International Conference on Hot Sheet Metal Forming of High-Performance Steel, Kassel, Germany, 22-24 October 2008.

[14] C. Boher, O. Barrau, R. Gras, F. Rezaï-Aria, A wear model based on cumulative cyclic plastic straining, Wear 267 (2009) 1087-1094. 